\title{
Materials and Processes for MEMS-Based Infrared Microspectrometer Integrated on $\mathrm{HgCdTe}$ Detector
}

\author{
Jaroslaw Antoszewski, Kevin J. Winchester, Member, IEEE, Thuyen Nguyen, \\ Adrian J. Keating, Senior Member, IEEE, K. K. M. B. Dilusha Silva, Charles A. Musca, Member, IEEE, \\ John M. Dell, Member, IEEE, and Lorenzo Faraone, Senior Member, IEEE
}

\begin{abstract}
The materials and processes for fabrication of monolithically integrated microelectromechanical systems-based microspectrometers operating in the short-wavelength IR range is presented. Using low-temperature surface micromachining techniques, compatible with a range of IR sensor technologies, siliconnitride-based tunable Fabry-Perot filter structures with distributed Bragg mirrors made of $\mathrm{Ge} / \mathrm{SiO} / \mathrm{Ge}$ layers have been monolithically integrated with $\mathrm{HgCdTe}$ photoconductors. The stress within and between the many layers of the structure has been eliminated or compensated by stress tuning of the deposition conditions. The demonstrated microspectrometers have a tuning range of 1.8$2.2 \mu \mathrm{m}$ with relative peak transmission of $70 \%$ and full-width at half-maximum of $80 \pm 10 \mathbf{n m}$.
\end{abstract}

Index Terms-IR detectors, IR filters, microelectromechanical systems (MEMS), microspectrometer.

\section{INTRODUCTION}

$\mathbf{E}$ XISTING IR detectors are sensitive over a broad spectral band, typically extending several microns below the cutoff wavelength. The detector output signal represents the total power of the incident IR radiation within the spectral range of the detector. Consequently, any quantitative information contained within the spectrum of the received IR radiation is not available. Many new and emerging applications require the detection of spectral features in the IR spectrum, thus allowing identification of the structure and composition of the various constituents present in the scene (see Fig. 1). The 1-15 $\mu \mathrm{m}$ range of the electromagnetic spectrum is the range over which most gases and chemicals of interest have strong rotational and vibrational absorptions, which can be used for identification and quantitative analysis of chemical composition. A range of commercial

Manuscript received December 9, 2007; revised February 14, 2008. This work was supported by the Australian Research Council and the Defense Science and Technology Organization of Australia.

J. Antoszewski, C. A. Musca, J. M. Dell, and L. Faraone are with the School of Electrical, Electronic and Computer Engineering, The University of Western Australia, Crawley, W.A. 6009, Australia (e-mail: jarek@ee.uwa.edu.au; johnd@ee.uwa.edu.au; charlie@ee.uwa.edu.au; faraone@ee.uwa.edu.au).

K. J. Winchester and K. K. M. B. D. Silva were with The University of Western Australia, Crawley, W.A. 6009, Australia. They are now with MRX Technologies Pty. Ltd., West Perth, W.A. 6005, Australia (e-mail: kjw@mrxtech.com.au; bds@mrxtech.com.au).

T. Nguyen was with The University of Western Australia, Crawley, W.A. 6009, Australia. He is now with Origin Energy Solar, Regency Park, S.A. 5010, Australia (e-mail: thuyen.nguyen@ originenergy.com.au).

A. J. Keating is with the School of mechanical Engineering, The University of Western Australia, Crawley, W.A. 6009, Australia (e-mail: keating@mech.uwa.edu.au).

Color versions of one or more of the figures in this paper are available online at http://ieeexplore.ieee.org.

Digital Object Identifier 10.1109/JSTQE.2008.919741

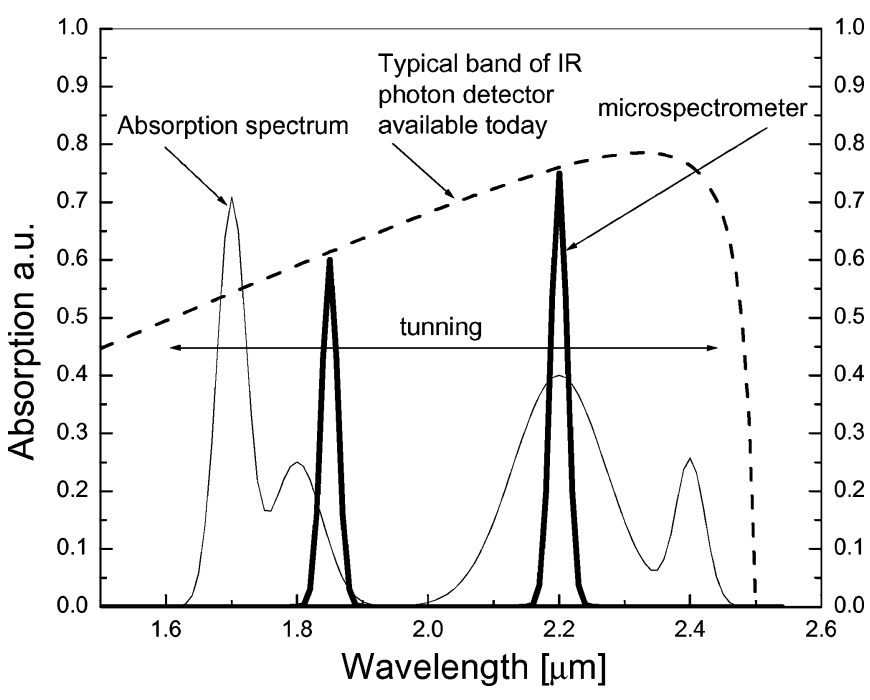

Fig. 1. Responsivity of present, broadband IR HgCdTe photon detector, and of the proposed tunable microspectrometer.

spectrometers is available for this purpose: however, potential applications of spectroscopic sensing in research and industry are often hampered by the size, cost, and lack of mechanical robustness of these instruments. Therefore, in recent years, a large research effort has been directed toward development of miniaturized and hence cost-effective, portable systems: mini- and microspectrometers. A comprehensive analysis of the progress achieved in this field can be found in a recent review article by Wolffenbuttel [1].

The first and obvious approach to developing a microspectrometer technology was microfabrication of individual optical components and their assembly, resulting in systems with dimensions of the order of $10 \mathrm{~cm}$. More recently, with the spectacular progress made in the technology of microelectromechanical systems (MEMS), fabrication of microspectrometer systems assembled on a microoptical platform of the size of $\leq 1 \mathrm{~cm}^{2}$ has become possible. Since not all of the components of such systems were compatible with silicon wafer processing, such devices have been developed using bulk micromachining of the various structures on two separate silicon wafers followed by bonding and packaging in the final step. Due to difficulties with beam splitter integration, the development of microspectrometers has concentrated on Fabry-Perot or Fourier transform interferometers with movable parts actuated electrostatically. Among the many design difficulties in these devices, reduction of the high voltages that are usually required to obtain sufficient actuation 
to scan IR wavelengths, and integration with high-performance IR photon detectors, appear to be the most challenging.

A technology attempting to address these issues in the shortwave IR (SWIR) has been reported recently, and is based on developing a low-temperature MEMS technology compatible with a broad range of compound semiconductors [2], [3]. In this approach, the materials and processes for fabrication of lowstress silicon nitride MEMS structures, deposited at temperatures below $200^{\circ} \mathrm{C}$, has been developed, and then, used in the surface micromachining process for monolithic integration of Fabry-Perot filters with HgCdTe-based short wavelength (1.6$2.5 \mu \mathrm{m}$ range) IR detectors. Low silicon nitride deposition temperature is required in order to limit the maximum temperature sustainable by most IR-sensitive materials, and in particular, by $\mathrm{HgCdTe}$ devices. Extensive studies of low-temperature silicon nitride deposition in a plasma-enhanced CVD (PECVD) system has resulted in a set of conditions that provides structures with appropriate mechanical properties and low internal stress that allows for significant reduction of actuation voltage [4]-[6].

The contents of this paper describe the materials, processes, and principles of this technology, device design, fabrication, and basic characterization.

\section{DEVICE CONCEPT}

The generic concept of the presented microspectrometer is based on a tunable Fabry-Perot microfilter monolithically integrated and optically ahead of the IR detector. The cross section of such a device is presented in Fig. 2. Being a typical construction material in MEMS technology, silicon nitride has been selected as the structural membrane material for a suspended flexible structure. It is deposited on a patterned polyimide layer that is used as a sacrificial layer. The filter requires fabrication of two Bragg mirrors, the lower one being fixed and deposited directly on the face of the IR detector and the upper one suspended on a flexible microstructure fabricated using a surface micromachining process. For both these mirrors, $\mathrm{Ge} / \mathrm{SiO} / \mathrm{Ge}$ layer stacks have been used. The filter can be tuned by changing the separation between the lower and upper Brag mirrors using an electrostatic force between two metal electrodes, one located below the lower mirror and the second on top of the suspended microstructure. This generic concept allows, in principle, for fabrication of devices operating in different IR bands by simply changing the gap between the mirrors and mirror materials and thicknesses. Having this in mind, IR detectors based on $\mathrm{HgCdTe}$ technology have been selected as a technology demonstrator, since they can be tailored to any range between 2 and $14 \mu \mathrm{m}$ by growing $\mathrm{HgCdTe}$ material of appropriate composition.

The fabrication of the microspectrometer structure as shown in Fig. 2 requires a number of major material and process requirements to be met in order to obtain an operational device. The first and fundamental one is the upper processing temperature limitation imposed by the temperature-sensitive $\mathrm{HgCdTe}$ detector. The second important requirement is flatness of the detector surface on which the Fabry-Perot filter is fabricated. Next, in order to achieve low actuation voltages required by the readout driver, fabrication of the thin actuating structural mem-

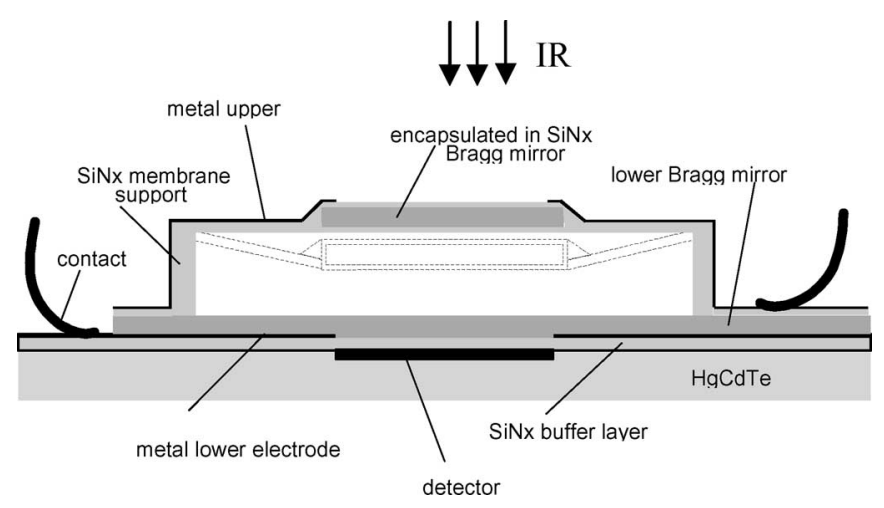

Fig. 2. General concept of a Fabry-Perot filter monolithically integrated on an IR photon detector.

brane requires low-stress silicon nitride, with sufficient mechanical strength. Finally, the last major requirement is low stress or stress compensation between the silicon nitride membrane and the upper Bragg mirror stack in order to avoid excessive bowing of the mirror. In the following sections, all these major requirements will be considered.

\section{Materials AND PROCESSES}

\section{A. Low Temperature, Low Stress $\mathrm{Si}_{x} \mathrm{~N}_{y}$}

The dominant technological constraint that needs to be adhered to is that all aspects of the monolithic integration of the IR detector with the MEMS filter must be implemented at a low enough temperature that is compatible with the maximum allowable thermal budget for the IR-sensitive material. For the $\mathrm{HgCdTe}$ detectors used in this study, the acceptable maximum temperature limit is $150^{\circ} \mathrm{C}$, which is much lower than for other IR-sensitive photon detectors. If $\mathrm{HgCdTe}$ is taken above this limit for an extended period of time, interdiffusion of dopants, defects, and atoms from contact metal, as well as outdiffusion of mercury will degrade device performance dramatically. Deposition of $\mathrm{Ge} / \mathrm{SiO} / \mathrm{Ge}$ layers for the Bragg mirror stacks is a relatively low-temperature process, and hence, does not create a problem if the samples are placed on appropriate heat sinks during deposition. On the other hand, as will be shown later, growth of high-quality, low-stress silicon nitride presents serious challenges.

In standard MEMS technology, electrostatically actuated structures using silicon nitride $\left(\mathrm{Si}_{x} \mathrm{~N}_{y}\right)$ are deposited using low-pressure chemical vapor deposition (LPCVD) [7]-[12]. Although capable of depositing very high-quality $\mathrm{Si}_{x} \mathrm{~N}_{y}$, the process requires high temperatures $\left(\sim 700^{\circ} \mathrm{C}\right)$, and results in films under considerable tensile stress. Consequently, the resulting structures are mechanically very stiff, such that the large deflections needed for IR micro-Fabry-Perot interferometer applications require very high actuator voltages. Conversely, compressive stress leads to collapse of the membrane when released from the sacrificial layer.

Our studies of low-temperature silicon nitride deposition in a PECVD system has resulted in a set of conditions that provides structures with appropriate mechanical properties and low 


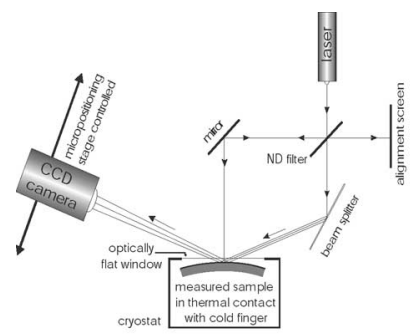

(a)

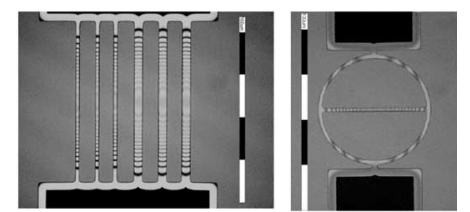

(b)
Fig. 3. Thin film stress measurement methods. (a) Three beam. (b) Stress sensitive microstructures (left: compressive; right: tensile). Black/white section of the scale $100 \mu \mathrm{m}$.

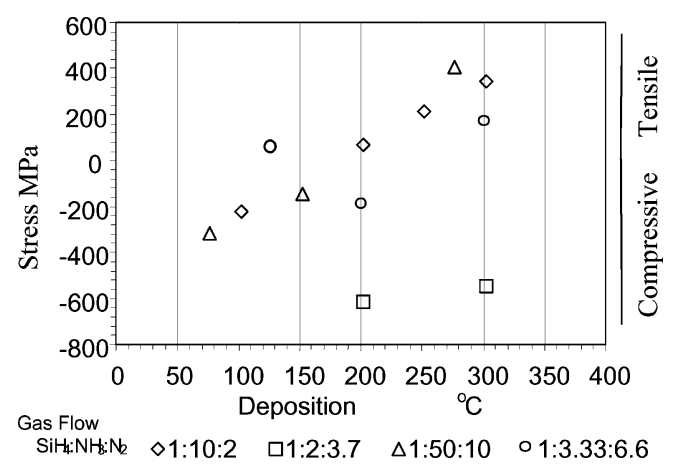

Fig. 4. Stress in silicon nitride layers versus deposition temperature for different process gas ratios. Open circle represents conditions used in the microspectrometer fabrication process: $p=865 \mathrm{mB}, T=125^{\circ} \mathrm{C}$, RF plasma power $p=$ $90 \mathrm{~W}$.

internal stress that also allows for significant reduction of actuation voltage [4]-[6], [13]-[18]. The stress in the silicon nitride layers has been assessed using two methods: the optical three beam method as illustrated in Fig. 3(a) that measures wafer bowing, and counting interference fringes in microstructures as shown in Fig. 3(b). The wafer-bowing approach and the use of localized test microstructures have been found to give comparable results.

Fig. 4 shows the results of stress measurements on silicon nitride layers deposited under different conditions. It demonstrates that the intrinsic stress in PECVD deposited silicon nitride can be varied from $400 \mathrm{MPa}$ tensile to approximately $600 \mathrm{MPa}$ compressive, by controlling the process gas ratios and substrate temperature [5], [6]. The open circle in this graph represents the conditions used for MEMS structural membrane fabrication for microspectrometers described in this paper. The process conditions have been optimized to intentionally produce $\mathrm{Si}_{x} \mathrm{~N}_{y}$ films with a very low level of tensile stress to avoid any buckling associated with compressively stressed structures. Under these conditions, the stress varied less then \pm 10 MPs from run to run.

\section{B. Actuated Structural Membrane}

The choice of the structural membrane needs to take into account such critical parameters as bowing, tilt, maximum deflection, maximum actuation voltage, stress gradients, etc. Stress gradients can arise due to changes in process parameters during

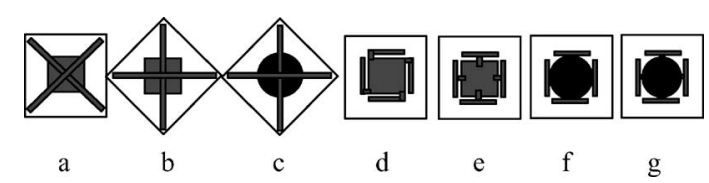

Fig. 5. Various membrane structures that were modeled. (a) Modified cross. (b) Plus. (c) Circular. (d) Hindu. (e)-(g) Three versions of T-shaped membranes.

thin film deposition and chemical interactions between different layers in the structure. Effective stress gradients can also arise due to thermal mismatch between the various layers. Different membrane shapes including the upper mirror layers have been modeled using the finite element analysis software package CoventorWare to explore the optimal design based on considerations of minimizing membrane deformation under maximum deflection, under the influence of stress gradients in the mirror and/or supports, and maximizing the optical fill factor. To simplify the model, the entire upper mirror stack $(\mathrm{Ge} / \mathrm{SiO} / \mathrm{Ge})$ was replaced by a single layer with an equivalent elastic modulus and density. The simplified mirror structure resulted in an error of less than $2 \%$ from the actual structure, but reduced computation time by up to $30 \%$. Fig. 5 summarizes the different design shapes modeled. The comparison of membrane/mirror bowing under the maximum deflection is shown in Fig. 6(a). The "Hindu" structure has the least amount of bowing because it is the most flexible structure. However, the "Hindu" structure is most sensitive to stress gradients, showing the largest flatness error for a stress gradient of $25 \mathrm{MPa} / \mu \mathrm{m}$, as shown in Fig. 6(b). The results shown in Fig. 6 indicate that no perfect structure exists and the best structure must be selected based on a compromise approach, which should consider the relative importance of critical parameters.

For the present study, the X-shaped membrane has been selected as a technology demonstrator. Although not optimal for minimal flatness error under maximum deflection, and with relatively low optical fill factor that renders it unsuitable for 2-D array applications, it assures good mechanical stability and insensitivity to stress gradient if deposited under slight tensile stress.

CoventorWare finite element analysis was undertaken to determine the $\mathrm{X}$-shape membrane displacement versus applied voltage (bias) characteristics and the critical voltage that results in snapdown. The results were compared with those produced by ANSYS (commonly used finite element modeling software). Consistent results were achieved between the two software modeling tools.

For the X-shaped membrane deflection modeling, the test structure consisted of a 450-nm-thick $\mathrm{Si}_{x} \mathrm{~N}_{y}$ layer and a 300 $\mathrm{nm}$ gold layer as the actuation electrode. A nominally identical structure was fabricated and experimentally tested. When actuated with a voltage bias of approximately $6.5 \mathrm{~V}$, a maximum displacement of $450 \mathrm{~nm}$ was achieved (the experimental data are shown as squares in Fig. 7). In order to match the model to experiment, a residual tensile stress of $20 \mathrm{MPa}$ had to be incorporated for the $\mathrm{Si}_{x} \mathrm{~N}_{y}$ layer in the model. Fig. 7 shows the model results with and without the incorporation of residual stress. 


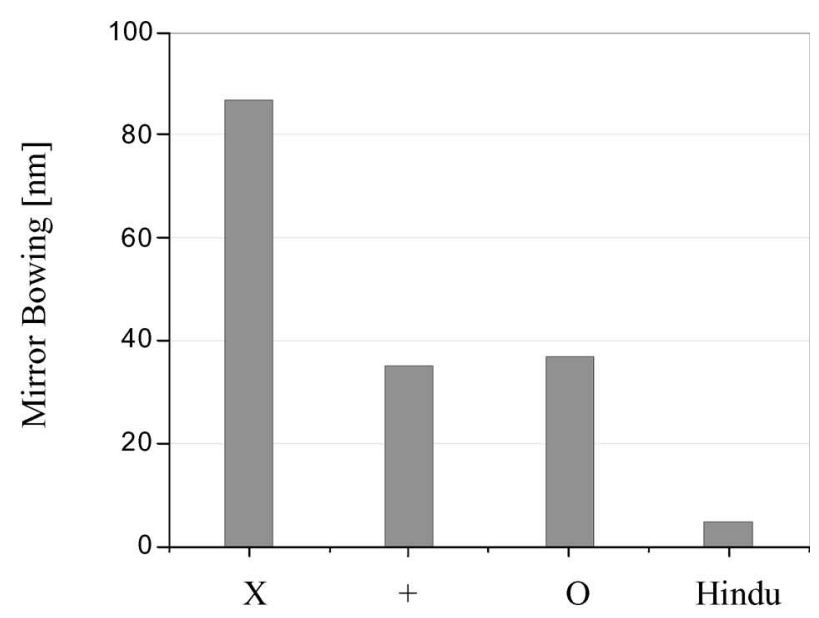

(a)

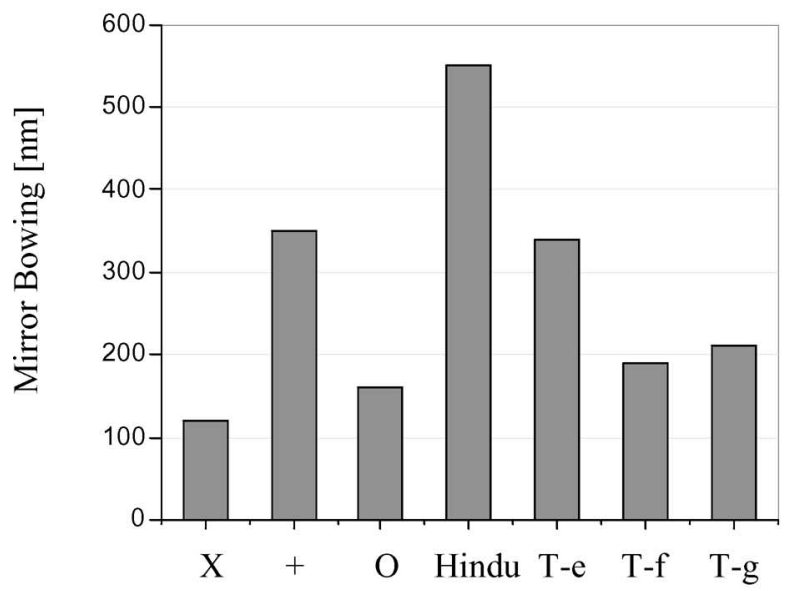

(b)

Fig. 6. (a) Membrane/mirror bowing at the maximum membrane deflection. (b) Membrane/mirror bowing caused by a relatively large stress gradient for various structures.

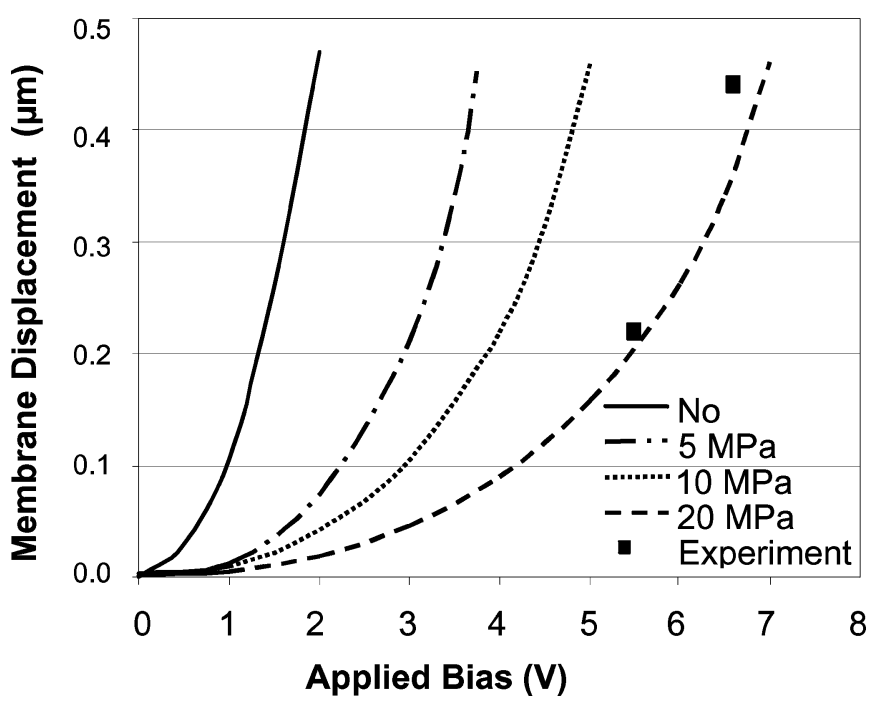

Fig. 7. Comparison between measured membrane displacement and modeled results. An intrinsic membrane stress of $\sim 20 \mathrm{MPa}$ must be included in the model in order to match the modeled and experimental results.

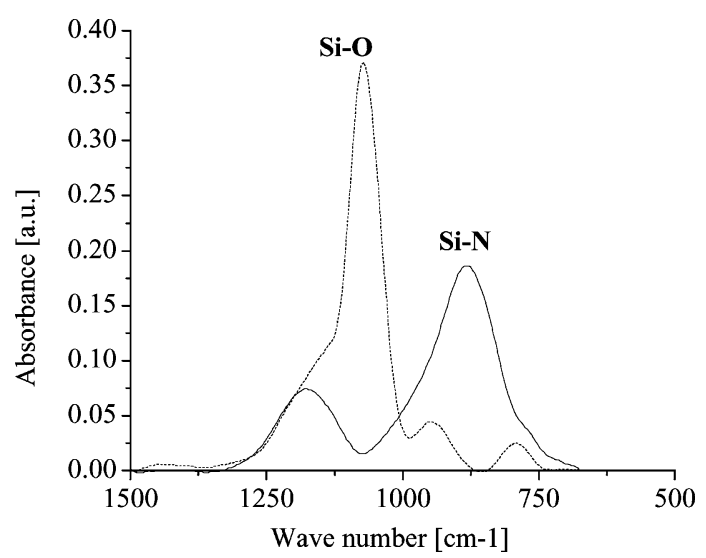

Fig. 8. Fourier transform infrared (FTIR) spectra of silicon nitride layer: as fabricated $(\mathrm{Si}-\mathrm{N})$ and after 90 min exposure to steam $(\mathrm{Si}-\mathrm{O})$.

\section{Sacrificial Layer and Release}

Polyimide has been adopted as the sacrificial layer since it has been used extensively in Si-based MEMS, in which it is usually removed by ashing in an $\mathrm{RF}$-induced $\mathrm{O}_{2}$ plasma. However, all attempts at a dry release process have resulted in producing high stress gradients in the $\mathrm{Si}_{x} \mathrm{~N}_{y}$ layers that exceed the acceptable levels for practical devices. Detailed studies of this effect have shown that it is a consequence of the low silicon nitride deposition temperature, which results in higher porosity, and consequently, sensitivity to environmental conditions. Structures exposed to air or oxygen plasma were found to have modified mechanical properties, including internal stress, with time of exposure. Two components of this environmental effect have been identified. The first, a reversible mechanism, is associated with moisture trapping. The membrane shape can only be recovered by baking if the exposure to air is relatively short (less than a few days). If exposure is much longer or is more extensive, as in the case of oxygen plasma, the second irreversible effect of oxidation of silicon nitride tends to dominate. In this process, silicon nitride is slowly converted to silicon oxide as shown in Fig. 8. Silicon oxide, having different mechanical properties, destroys the stress balance in the structure, and consequently, leads to device failure.

Consequently, as an alternative, a wet polyimide release process has been adopted in which devices are being released using wet etching in polyimide developer and dried using a $\mathrm{CO}_{2}$ critical point dryer (CPD). It was found that the CPD process does not introduce any stress in the released structures, and is relatively fast (see Fig. 9).

Another effect, which has to be taken into account when preparing the sacrificial layer, is its shrinkage due to partial curing in subsequent processing stages. Typically, the polyimide layers used in Si-based applications undergo heat treatments at temperatures $>300^{\circ} \mathrm{C}$ to fully cure (cross link) the material, resulting in low intrinsic stress and high strength. However, in order to ensure compatibility between MEMS and $\mathrm{HgCdTe}$ processing, the polyimide used as a sacrificial layer cannot be completely cured since full curing requires temperatures that are unacceptably high for $\mathrm{HgCdTe}$ processing. The partial 


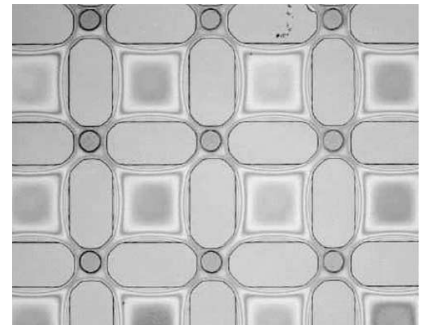

(a)

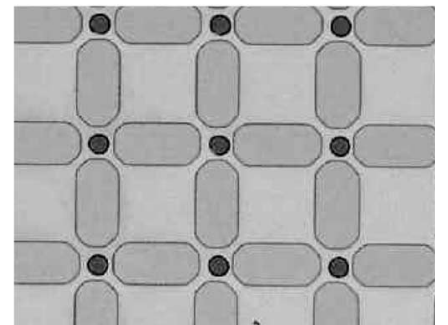

(b)
Fig. 9. Interference contrast photomicrographs of membranes released. (a) Dry process. (b) Wet process.

polyimide curing process that has been developed to overcome the $\mathrm{HgCdTe}$ process temperature limitations results in a number of nonideal behaviors. During the initial partial curing process (baking $10 \mathrm{~min}$ at $125{ }^{\circ} \mathrm{C}$ immediately following spinning of the polyimide), the polyimide layer thickness decreases by approximately $20 \%$, and reduces even further during subsequent processing, especially during $\mathrm{Si}_{x} \mathrm{~N}_{y}$ deposition. Due to this effect, the actual polyimide thickness is less than the expected spacer thickness, resulting in reduced or shifted tuning range in fabricated devices. This effect has been characterized and must be taken into account in the process design for the correct cavity length to be achieved. The polyimide shrinkage also causes a stress gradients observed in $\mathrm{Si}_{x} \mathrm{~N}_{y}$ layers as shown in Fig. 10, which can be reduced to an acceptable level by curing the polyimide at temperatures slightly higher than the reminder of the process. Taking all of the aforementioned factors into account, stress-free membranes can be obtained as shown in Fig. 10. These issues related to inaccurate curing of the polyimide sacrificial layer are not expected to be significant for other IR-sensitive materials that can sustain temperatures much higher than $\mathrm{HgCdTe}$.

\section{Distributed Bragg Mirrors}

1) Mirror Flatness: Optical flatness of the Bragg mirrors is a principal requirement for good performance of the Fabry-Perot filter. The flatness of the lower mirror is primarily determined by the flatness of the underlying $\mathrm{HgCdTe}$ material and detector structure, which has been estimated using surface profiling (DEKTAK). The sample used for this scan had nominal thickness of $5.18 \mu \mathrm{m}$, capped with $0.993 \mu \mathrm{m}$ of CdTe and $0.218 \mu \mathrm{m}$ of $\mathrm{ZnS}$. The profile of the surface scan is shown in Fig. 11. It indicates variations in local surface topology of the order of 50 $\mathrm{nm}$ over a $500 \mu \mathrm{m}$ distance. This surface topology, caused by wafer lapping and mechanic-chemical polishing, will affect the full-width at half-maximum (FWHM) of the Fabry-Perrot filter since the cavity length will vary accordingly. However, since the lateral size of the filter is of the order of $100 \mu \mathrm{m}$, the average of these surface profile variations is of the order of $25 \mathrm{~nm}$.

The flatness of the upper mirror is determined by the flatness of the polyimide sacrificial layer and the surface profile of the underlying layers. For the case of mesa-isolated detectors, the presence of relatively deep mesas affects the polyimide sacrificial layer surface topology. Fig. 12 shows an interfer-

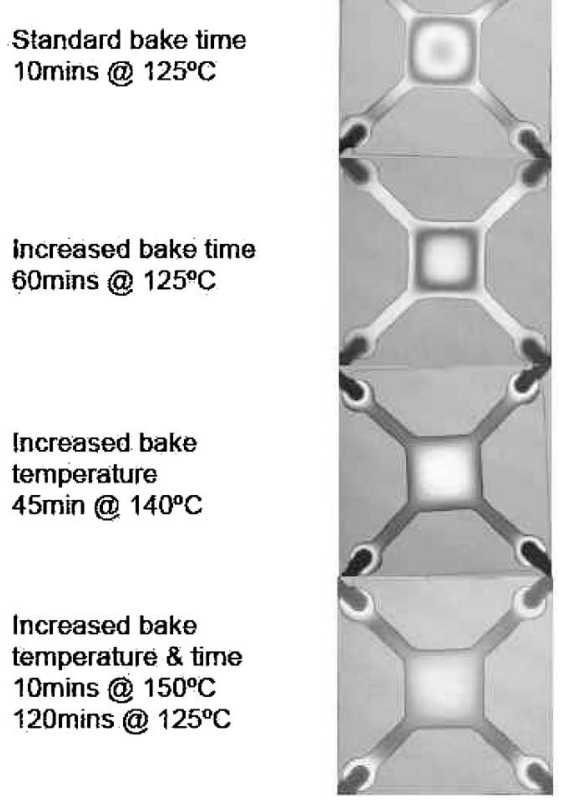

Fig. 10. Interference contrast micrographs showing the effect of polyimide shrinkage (caused by partial curing) on stress in the $\mathrm{Si}_{\mathrm{x}} \mathrm{N}_{\mathrm{y}}$ membrane. The presence of fringes is an indication of bowing.

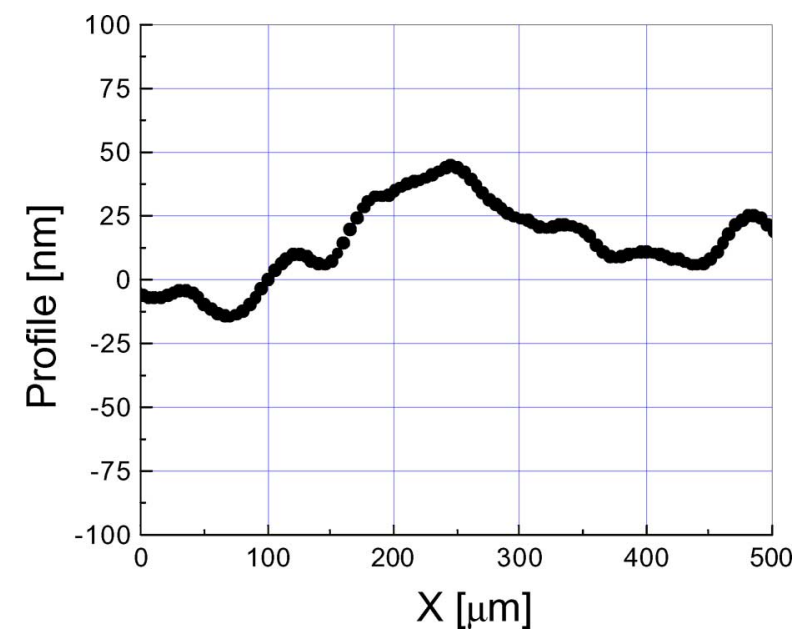

Fig. 11. 500- $\mu \mathrm{m}$-long profile across the $\mathrm{HgCdTe}$ wafer.

ence contrast micrograph of a polyimide island after polyimide patterning during simple filter fabrication on a silicon wafer, which does not have any mesas, and on an island of the same dimensions as the $\mathrm{HgCdTe}$ mesa. The difference in polyimide layer uniformity is clearly visible for mesa-isolated structures. The membrane and upper mirror deposited on the polyimide layer on the $\mathrm{HgCdTe}$ mesa may not necessarily be parallel to the lower mirror. This is likely to result in: 1) widening of the FWHM of the spectral response of the filter and 2) nonuniform membrane deflection since the charge will concentrate at the point of narrowest separation between the upper and lower electrode, effectively increasing any preexisting mirror tilt.

In addition to mesa-isolated photoconductors, two other detector structures have been briefly investigated, namely planar 


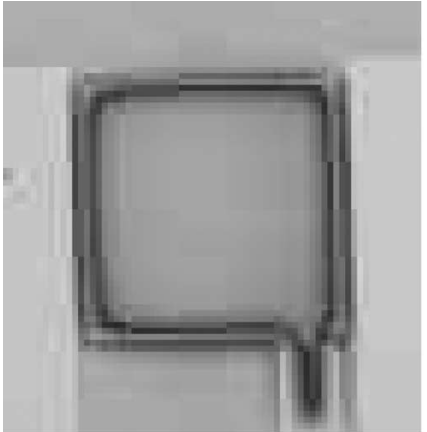

(a)

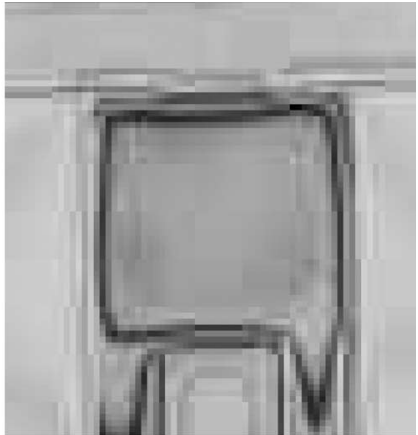

(b)
Fig. 12. Interference contrast micrograph. (a) Polyimide spun on a simple filter structure fabricated on silicon (no mesas). (b) Polyimide spun on a $\mathrm{HgCdTe}$ mesa. The presence of fringes is an indication of polyimide surface nonuniformities.

Corbino structures and planar diodes with relatively small steps present on the wafer surface (of the order of $200 \mathrm{~nm}$ ). It was found that much better polyimide flatness, comparable to that observed in Fig. 12(a), can be obtained. However, the disadvantage of both these approaches is that the detector fabrication process is much more complex. Therefore, as a demonstration vehicle in this project, the much simpler mesa-isolated detector structures have been adopted.

2) Mirror Structure: For high-resolution Fabry-Perot filters, loss within the cavity must be minimized. Metal mirrors, while having a broad spectral range, are generally a poor choice because of high absorption in the metal at IR wavelengths. Therefore, the mirrors used in Fabry-Perot filters are generally quarter-wave, dielectric-stack Bragg mirrors, fabricated from alternating layers of high and low refractive index transparent materials, with an optional thickness of $\lambda / 4$ at the center design wavelength. Of the readily available materials in our laboratory, germanium and silicon monoxide have been selected as high and low refractive index materials, respectively. Both five-layer and three-layer $\mathrm{Ge} / \mathrm{SiO}$ mirror stacks have been investigated but as a compromise between optical performance and low mirror mass, the three-layer structures have been selected for fabrication. Fig. 13 presents the modeled results of Fabry-Perot filter transmission and the impact of structure bowing. The FWHM for the ideal case with a flat mirror and the more realistic with $80 \mathrm{~nm}$ of mirror curvature has been estimated to be $\sim 35$ and $\sim 55 \mathrm{~nm}$, respectively.

Originally, the lower mirror was also designed to act as the lower electrode. This was achieved by depositing a very thin layer of indium onto the first germanium layer during the lower mirror deposition process. The presence of the indium layer slightly modified the mirror absorption at $2.2 \mu \mathrm{m}$ from $8 \%$ to $12 \%$. In order to test the conductivity of this layer, the lower mirror stack has been deposited on sapphire with two $\mathrm{Cr} / \mathrm{Au}$ pads. The resistance between the pads varied between runs, but was always within an acceptable range of 10-100 $\mathrm{k} \Omega$. Later in the process development, a different approach has been adopted. It was found that deposition of a thin $\mathrm{Cr} / \mathrm{Au}$ electrode under the lower mirror stack (with window under the active area of the filter) performs with equivalent efficiency. It does not affect

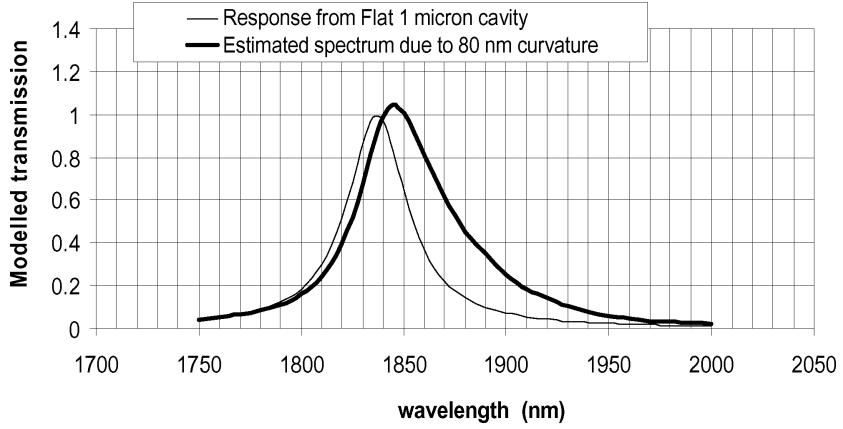

Fig. 13. Modeled transmission spectral response from a nominally flat mirror with a $1 \mu \mathrm{m}$ gap and the effect of an $80 \mathrm{~nm}$ bow in the $100 \mu \mathrm{m} \times 100 \mu \mathrm{m}$ mirror.

significantly either the polyimide uniformity, or the deflectionvoltage characteristics of the structure. In addition, when extended laterally, it can be used as an efficient optical shield for any unfiltered or scattered IR light bypassing the filter.

3) Stress in Mirrors and Compensation: The stack of $\mathrm{Ge} / \mathrm{SiO} / \mathrm{Ge}$ layers used for Bragg mirrors is not free of stress itself. Initial experiments on sacrificial layer release demonstrated large stress in the mirror stacks causing unacceptable bending and distortion. Hence, an intensive study was undertaken to identify any sources of stress and to develop process to mitigate such effects. Test structures in the form of cantilevers were fabricated of either germanium or silicon monoxide deposited on $\mathrm{Si}_{x} \mathrm{~N}_{y}$ membranes. These tests showed that stress in germanium layers is minimal, whereas the intrinsic stress in silicon monoxide is relatively large. In order to minimize the stress in the $\mathrm{SiO}$, a technology based on control of the deposition chamber pressure, primarily by admitting oxygen, water vapor, or room air during $\mathrm{SiO}$ evaporation [19], [20], has been successfully applied.

On the other hand, the differential stress between $\mathrm{Ge} / \mathrm{SiO} / \mathrm{Ge}$ mirror stack and the silicon nitride membrane has been reduced by fabrication of a symmetrical mirror/membrane structure by introducing a second silicon nitride overlayer, identical to the lower one, in order to encapsulate the mirror stack. This effect is illustrated in the interference contrast micrographs shown in Fig. 14. The presence of interference fringes indicate deformation along the support arms, while the shading in the center mirror regions (which are opaque to the illuminating wavelength and hence cannot generate interference fringes) is also indicative of bowing. It should be noted that the layers used to form the structures shown in Fig. 14(a) and (b), consisting of the $\mathrm{Si}_{x} \mathrm{~N}_{y}$ membrane with a mirror stack deposited on top (no encapsulation) are very sensitive to even small residual stresses in contrast to encapsulated ones [see Fig. 14(c) and (d)]. It is clear from this figure that encapsulation has significantly reduced bowing of the suspended mirror/membrane structure.

Fig. 15 shows the modeled upper mirror displacement as a function of applied bias for encapsulated structures together with experimental measurements (open circles). It can be seen that the modeled displacement for stress-free $\mathrm{Si}_{x} \mathrm{~N}_{y}$ layers shows some discrepancy with the measurements indicated by open circles. The measured data fit between the modeled displacement curves 

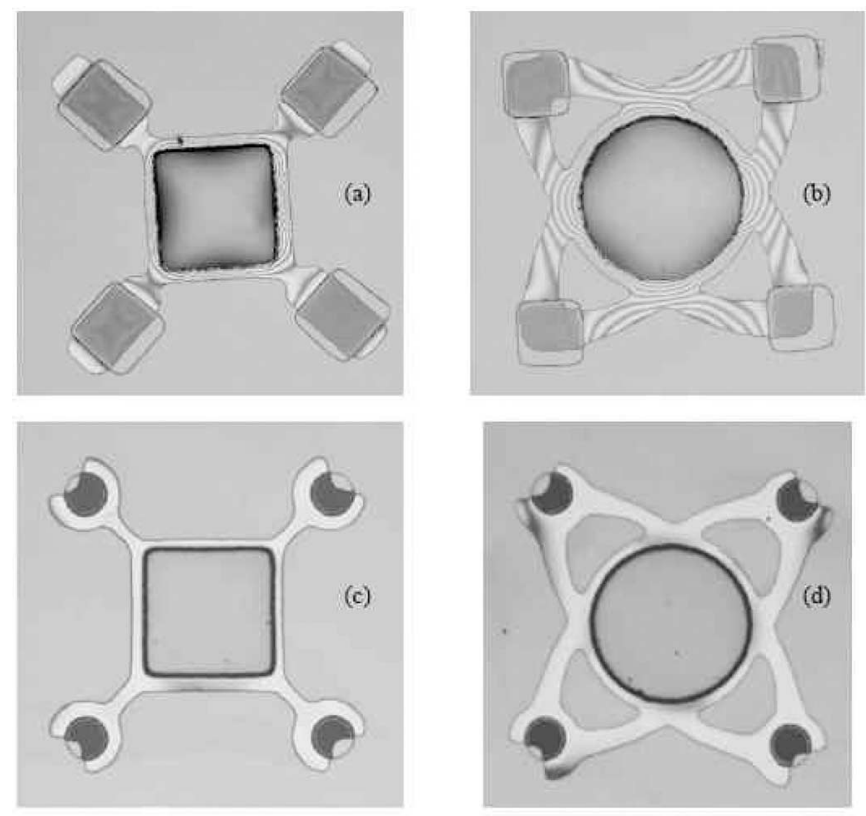

Fig. 14. Interference contrast micrographs of two different types of support structures. (a) and (b) Single layer of $\mathrm{Si}_{\mathrm{x}} \mathrm{N}_{\mathrm{y}}$ below the central mirror region. (c) and (d) Central mirror region encapsulated with $\mathrm{Si}_{\mathrm{x}} \mathrm{N}_{\mathrm{y}}$ above and below the mirror. The fringing evident in the transparent $\mathrm{Si}_{\mathrm{x}} \mathrm{N}_{\mathrm{y}}$ layers and the shading in the central mirror regions in (a) and (b) are indicative of bowing on the suspended mirror/membrane structure.

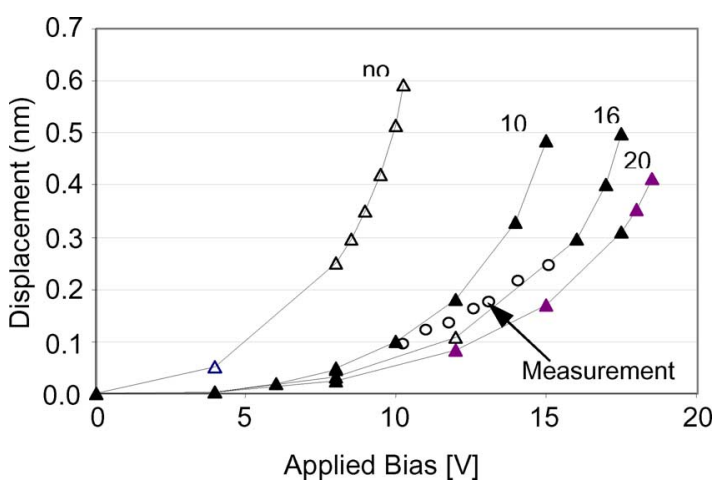

Fig. 15. Modeled relationship between mirror/membrane displacement and applied bias for the $\mathrm{Si}_{\mathrm{x}} \mathrm{N}_{\mathrm{y}}$ encapsulated model. Various $\mathrm{Si}_{\mathrm{x}} \mathrm{N}_{\mathrm{y}}$ residual stresses were incorporated in the encapsulated model.

with $\mathrm{Si}_{x} \mathrm{~N}_{y}$ residual tensile stresses of 10 and $16 \mathrm{MPa}$, possibly indicating that the encapsulated structure has resulted in an average stress in the $\mathrm{Si}_{x} \mathrm{~N}_{y}$ layer that is slightly less than the $20 \mathrm{MPa}$ observed in the initial test devices without mirrors (see Fig. 7).

4) Stress in Thermally Evaporated Cr/Au Layers: In addition to the stress observed in $\mathrm{Si}_{x} \mathrm{~N}_{y}$ and $\mathrm{SiO}$, it was found that the metal layers needed for contact to the top electrode also contribute to the total stress in the actuated structure and needed to be minimized. Again, test structures with cantilevers were used to evaluate stress in metal layers, with stress evaluated for $\mathrm{Au}$ single layer films as well as $\mathrm{Cr} / \mathrm{Au}$ double-layer films. The graph shown in Fig. 16 presents a summary of the stress investigation in $\mathrm{Cr} / \mathrm{Au}$ films. The optimum conditions have been obtained for $1 \mathrm{~nm}$ of $\mathrm{Cr}$ and $30 \mathrm{~nm}$ of $\mathrm{Au}$, deposited at low rates of

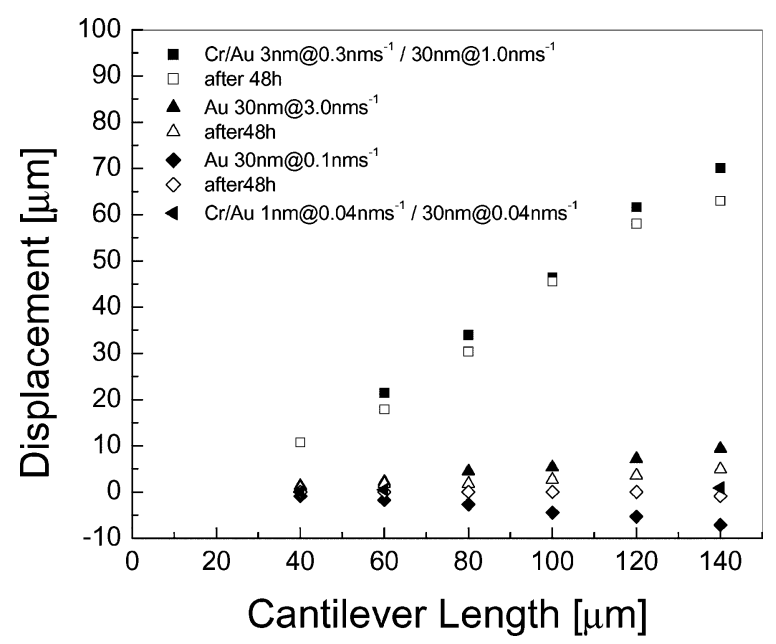

Fig. 16. Displacement of the tip of $\mathrm{a} \mathrm{Si}_{\mathrm{x}} \mathrm{N}_{\mathrm{y}}$ cantilever beam after coating with various metallization. Positive displacement corresponds to tensile stress in the metal while negative displacement corresponds to compressive stress.

approximately $0.04 \mathrm{~nm} / \mathrm{s}$ to achieve low-stress composite metal layers.

\section{DEVICE FABRICATION}

The concept-demonstrator device consists of an HgCdTebased mesa-isolated photoconductive detector combined with a monolithically integrated MEMS-based optical filter positioned between the individual detector and the radiation source, as shown in Fig. 2. The mesa defined $\mathrm{HgCdTe}$ photoconductive devices with an optical width of $300 \mu \mathrm{m}$ and length of 340 $\mu \mathrm{m}$ are isolated from the filter structure by a buffer layer of silicon nitride. On top of this layer, the lower electrode of the filter, with $90 \mu \mathrm{m} \times 90 \mu \mathrm{m}$ optical window in the center, is fabricated followed by thermal deposition of the lower Bragg mirror, consisting of $\mathrm{Ge} / \mathrm{SiO} / \mathrm{Ge}$ layers. Next, the polyimide sacrificial layer is spun onto the wafer, cured and patterned via a photoresist mask in a dry etching process to provide the pattern for the silicon nitride membrane structure with cylindrical supports for stiffness as shown in the SEM picture (see Fig. 17). Silicon nitride was deposited using PECVD at $125^{\circ} \mathrm{C}$, followed by the upper Bragg mirror deposition and liftoff stage and a second silicon nitride overlayer to encapsulate the upper mirror. The shape of the membrane and arms is defined by a patterned 30-nm-thin layer of $\mathrm{Cr} / \mathrm{Au}$, which acts as the upper electrode, in a photolithographic step followed by dry etch in $\mathrm{CF}_{4}$ plasma. The brighter regions on the supports, visible in the SEM photograph of Fig. 17, are formed by a layer of thick gold to ensure metal continuity over the steep sidewall of the cylindrical support structures. Finally, the mirror/membrane and arms structure is released by dissolving the polyimide sacrificial layer in developer bath followed by the critical point drying process.

In order to avoid any damage caused by snapdown, which makes measurements of these devices very difficult, and consequently, slows the pace of technology development, an extra processing step has been added to form $\sim 0.5 \mu \mathrm{m}$ deep 


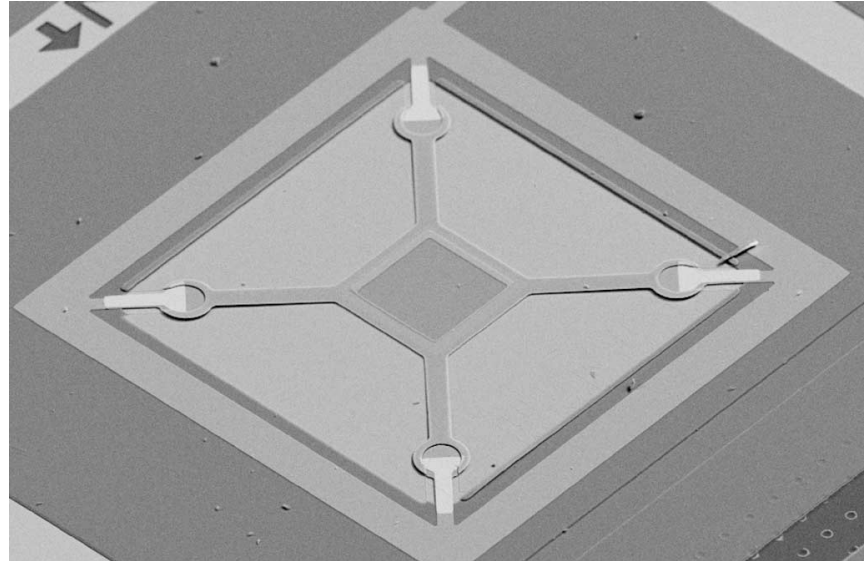

Fig. 17. SEM picture of an integrated Fabry-Perot filter and photoconductor structure.

antistiction bumps at the edges of the membrane. Due to their very small area, the stiction forces between the membrane and the substrate (lower mirror) have been reduced below the pulling forces present in the arms, allowing for full device recovery even from a collapsed position [21], [22]. During tests, the full collapse-recovery cycle has been repeated many times, proving the effectiveness of the antistiction bumps. This minor addition to the processing sequence allows for measurements to be continued even after membrane collapse, which may occur due to electrostatic charges or accidental voltage drive above the snapdown limit.

In order to verify the electrical isolation between the filter and photoconductor, two types of isolation were investigated, a single 550-nm-thick layer of $\mathrm{Si}_{x} \mathrm{~N}_{y}$, both with and without $\sim 100$-nm-thick native oxide grown on the underlying $\mathrm{HgCdTe}$ layer. The thickness of the isolation layer has been optimized taking into account electrical isolation and optical properties. Electrical tests of photoconductors showed good ohmic contacts with photoconductor dark resistance between 2 to $4 \mathrm{k} \Omega$ at room temperature, depending on the $\mathrm{HgCdTe}$ layer thickness. The isolation between lower and upper electrodes was $>10^{10} \Omega$. Similar isolation was measured between both electrodes and the photoconductor contacts regardless of the type of isolation used (with oxide or without). Therefore, only the $\mathrm{Si}_{x} \mathrm{~N}_{y}$ isolation layer has been used in subsequent device fabrication runs. On the same wafer full microspectrometer structures with two different arm lengths (50 and $100 \mu \mathrm{m}$ ) have been fabricated. In addition, several test devices including reference photoconductor, photoconductor with lower mirror only, photoconductor with upper mirror only, stress test structures, $\mathrm{Si}_{x} \mathrm{~N}_{y}$ membranes without mirrors (transparent) required in order to monitor the polyimide release under an optical microscope, reference unreleased devices, and islands of individual layers for thickness measurements. Photographs presented in Fig. 18 show three stages of deflection of a monolithically integrated spectrometer/HgCdTe photoconductor device with $100 \mu \mathrm{m}$ arms. The zero bias image [see Fig. 18(a)] shows almost no interference fringes. Fig. 18(b) shows the device under moderate bias, while Fig. 18(c) shows the device after snapdown. By counting inter-

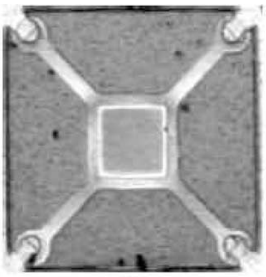

(a)

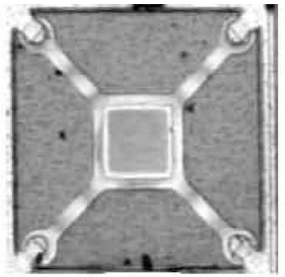

(b)

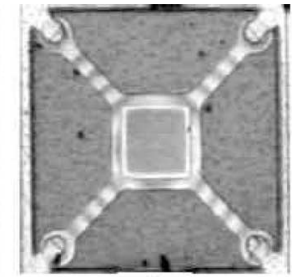

(c)
Fig. 18. Spectrometer tuning. (a) Zero bias. (b) Moderate bias. (c) After snapdown. In these three successive interference contrast micrographs, the number of interference fringes increases almost identically on all four arms demonstrating very good membrane parallelism. This device deflects by $\sim 500 \mathrm{~nm}$ before snapdown.

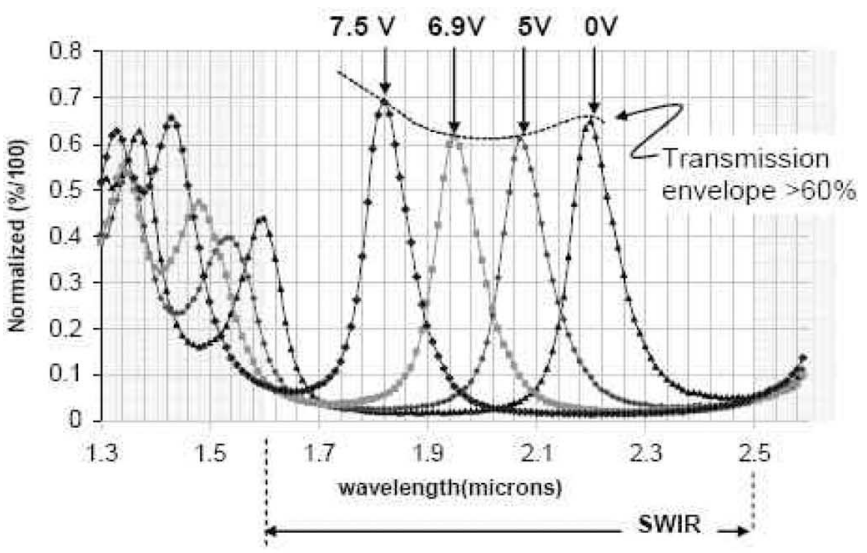

(a)

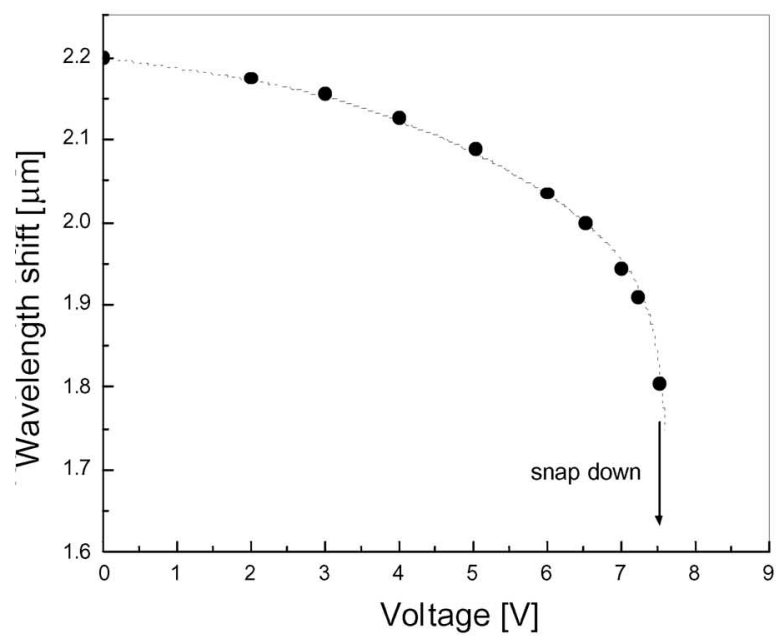

(b)

Fig. 19. (a) Optical transmission spectra of SWIR filter obtained for driving voltage range from 0 to $7.5 \mathrm{~V}$. (b) Wavelength shift $\sim 0.4 \mu \mathrm{m}$ for $0-7.5 \mathrm{~V}$ range followed by membrane snap down at $1 / 3$ of the gap.

ference fringes, the membrane deflection was estimated to be $\sim 500 \mathrm{~nm}$ just before snapdown.

\section{DEVICE CHARACTERIZATION}

The optical performance of fabricated devices has been assessed by performing IR responsivity measurements in the spectral range from 1.5 to $2.5 \mu \mathrm{m}$. The spectra obtained for applied voltage in the range from 0 to $7.5 \mathrm{~V}$ are shown in Fig. 19(a). 
The spectral band of the filter is defined by the distributed Bragg mirror characteristics, represented by an increase in transmission at both short and long wavelength ends of the spectrum. The maximum optical transmission at the peak is of the order of $70 \%$. The filter demonstrates good extinction ratio, $\sim 35$ across the tuning range. The FWHM has been estimated to be $80 \pm$ $10 \mathrm{~nm}$. The tuning spans from $2.2 \mu \mathrm{m}$ at $0 \mathrm{~V}$ to $1.8 \mu \mathrm{m}$ at $\sim 7.5 \mathrm{~V}$, which, as noted previously, relates to displacement of the mirror by $\sim 1 / 3$ of the cavity. Fig. 19(b) shows the filter's highly nonlinear tuning curve with the theoretical characteristic indicated by a dashed line. At $7.5 \mathrm{~V}$, the membrane approaches the point of instability, and eventually, snaps down. This effect can be partially eliminated by using techniques investigated earlier such as charge control [23], geometry leverage [24], series feedback capacitor [25]-[27], current drive methods [28]-[30], closed-loop voltage control [31]-[33], modification of support beams [34], and voltage drive approach [35].

It is important to note that, due to development of low-stress silicon nitride and stress balancing in the membrane/mirror structure, the large wavelength tuning range of $0.4 \mu \mathrm{m}$ has been obtained with a relatively low driving voltage of only $7.5 \mathrm{~V}$, which is acceptable for IR detectors fabricated using compound semiconductors such as $\mathrm{HgCdTe}$, and consequently, makes monolithic integration possible for 2-D focal plane array applications.

\section{CONCLUSION}

In this paper, recent progress in the development of MEMS materials and process technology compatible with compound semiconductors has been presented. The microspectrometer tuning in the range of $1.8-2.2 \mu \mathrm{m}$ has been demonstrated. However, at this early stage of development, the $\sim 80 \mathrm{~nm}$ FWHM needs to be narrowed in order to be applicable for precise spectrometer applications. The tuning range can be extended by using more sophisticated control of the membrane deflection. The SWIR filter monolithically integrated with $\mathrm{HgCdTe}$ detector has been used as a demonstration vehicle. However, with some adjustments in the design and modifications in the processing, it can be extended to the mid-wave IR (MWIR) range and beyond and readily transferred to other detector materials.

The materials and processes are quite complex and at the moment require 12 photolithographic steps, as well as precise control of process parameters. The fabrication process could be significantly simplified if low-stress nickel or titanium was developed as structural material instead of $\mathrm{Si}_{\mathrm{x}} \mathrm{N}_{\mathrm{y}}$. Also, elimination of $\mathrm{Si}_{\mathrm{x}} \mathrm{N}_{\mathrm{y}}$ from the filter cavity should result in improved optical performance.

\section{REFERENCES}

[1] R. F. Wolffenbuttel, "MEMS-based optical mini- and microspectrometers for the visible and infrared spectral range," J. Micromech. Microeng., vol. 15, pp. S145-S152, 2005.

[2] J. Antoszewski, K. J. Winchester, A. J. Keating, T. Nguyen, K. K. M. B. D. Silva, C. A. Musca, J. M. Dell, L. Faraone, P. Mitra, J. D. Beck, M. R. Skokan, and J. E. Robinson, "A monolithically integrated $\mathrm{HgCdTe}$ short-wavelength infrared photodetector and micro-electro-mechanical system-based optical filter," TMS/IEEE J. Electron. Mater., vol. 34, no. 6, pp. 716-721, Jun. 2005.
[3] C. A. Musca, J. Antoszewski, K. J. Winchester, A. J. Keating, T. Nguyen, K. K. M. B. D. Silva, J. M. Dell, L. Faraone, P. Mitra, J. D. Beck, M. R. Skokan, and J. E. Robinson, "Monolithic integration of an infrared photon detector with a MEMS-based optical filter," IEEE Electron Device Lett., vol. 26, no. 12, pp. 888-890, Dec. 2005.

[4] H. Huang, K. J. Winchester, Y. Liu, X. Z. Hu, C. A. Musca, J. M. Dell, and L. Faraone, "Determination of mechanical properties of PECVD silicon nitride thin films for tunable MEMS Fabry-Perot optical filters," J. Micromech. Microeng., vol. 15, pp. 608-614, 2005.

[5] B. A. Walmsley, Y. Liu, X. Z. Hu, M. B. Bush, K. J. Winchester, M Martyniuk, J. M. Dell, and L. Faraone, "Effects of deposition temperature on the mechanical and physical properties of silicon nitride thin films," J. Appl. Phys., vol. 98, no. 4, pp. 044904-1-044904-6, 2005.

[6] M. Martyniuk, J. Antoszewski, C. A. Musca, J. M. Dell, and L. Faraone, "Stress in low temperature plasma enhanced chemical vapour deposited silicon nitride thin films," Smart Mater. Struct., vol. 15, pp. S29-S38, 2006.

[7] I. Kobayashi, T. Ogawa, and S. Hotta, "Plasma-enhanced chemical vapor deposition of silicon nitride," Jpn. J. Appl. Phys., vol. 31, pp. 336-342, 1992.

[8] W. A. P. Classen, W. G. J. N. Valkenburg, F. M. C. Willemsen, and W. M. v. d. Wijgert, "Influence of deposition temperature, gas pressure, gas phase composition, and RF frequency on composition and mechanical stress of plasma silicon nitride layers," J. Electrochem. Soc.: Solid-State Sci. Technol., vol. 132, no. 4, pp. 893-898, 1985.

[9] D. L. Smith, A. S. Alimonda, C.-C. Chen, S. E. Ready, and B. Wacker, "Mechanism of SiNxHy deposition from NH3-SiH4 plasma," J. Electrochem. Soc., vol. 137, no. 2, pp. 614-623, 1990.

[10] A. Stoffel, A. Kovacs, W. Kronast, and B. Muller, "LPCVD against PECVD for micromechanical applications," in Proc. 6th Eur. Workshop Micromech. (MME 1995), Copenhagen, Denmark, pp. 1-13.

[11] M. Shenasa, M. Moinpour, B. O’Toole, B. Stueve, R. Wilkes, J. Reece, D. Borror, and J. Glarneau, "Optimization of LPCVD silicon nitride process in a vertical thermal reactor: Use of design of experiments," in Proc. IEEE/SEMI 1992, Adv. Semicond. Manuf. Conf. (ASMC 92) Workshop, pp. 216-219.

[12] M. Modreanu, N. Tomozeiu, P. Cosmin, and M. Gartner, "Physical-optical properties of LPCVD amorphous silicon rich-nitride and oxynitride," in Proc. 1998 Int. Semicond. Conf., CAS 1998, vol. 1, pp. 201-204.

[13] H. Huang, K. J. Winchester, Y. Liu, X. Z. Hu, C. A. Musca, J. M. Dell, and L. Faraone, "Determination of mechanical properties of PECVD silicon nitride thin films for tunable MEMS Fabry-Perot optical filters," $J$. Micromech. Microeng., vol. 15, pp. 608-614, 2005.

[14] T. M. K. Soh, N. Savvides, C. A. Musca, M. P. Martyniuk, and L. Faraone, "Local bonding environment of plasma deposited nitrogen-rich silicon nitride thin films," J. Appl. Phys., vol. 97, no. 9, pp. 093714-1-093714-8, 2005.

[15] T. M. K. Soh, C. A. Musca, N. Savvides, J. M. Dell, and L. Faraone, "Evaluation of plasma deposited silicon nitride thin flims for microsystems technology," IEEE/ASME J. Microelectromech. Syst., vol. 14, no. 5, pp. 971-977, Oct. 2005.

[16] T. M. K. Soh, T. Nguyen, K. K. M. B. D. Silva, R. J. Westerhout, J. Antoszewski, A. J. Keating, N. Savvides, C. A. Musca, J. M. Dell, and L. Faraone, "Short-wavelength infrared tuneable filters on $\mathrm{HgCdTe}$ photoconductors," Opt. Exp., vol. 13, no. 24, pp. 9683-9694, 2005.

[17] H. Huang, X. Z. Hu, Y. Liu, M. Bush, K. J. Winchester, C. A. Musca, J. M. Dell, and L. Faraone, "Characterization of mechanical properties of silicon nitride thin films for MEMS devices by nanoindentation," $J$. Mater. Sci. Technol., vol. 21, no. 1, pp. 13-16, 2005.

[18] B. A. Walmsley, Y. Liu, X. Z. Hu, M. B. Bush, K. J. Winchester, M. Martyniuk, J. M. Dell, and L. Faraone, "Effects of deposition temperature on the mechanical and physical properties of silicon nitride thin films," $J$. Appl. Phys., vol. 98, pp. 044904-1-044904-6, 2005.

[19] M. A. Novice, "Effect of atmospheric exposure on stress in evaporated silicon monoxide films," Br. J. Appl. Phys., vol. 13, pp. 561-563, 1962.

[20] A. E. Hill and G. R. Hoffman, "Stress in films of silicon monoxide," $B r$. J. Appl. Phys., vol. 18, pp. 13-22, 1967.

[21] R. Gissi and P. Decuzzi, "The effect of shape and size in micro/nanodimples adhesion," J. Appl. Phys., vol. 98, pp. 014310-1-014310-9, 2005.

[22] J. Bico, C. Marzolin, and D. Quéré, "Peral drops," Europhys. Lett., vol. 47, pp. 220-226, 1999.

[23] J. I. Seeger, "Charge control of parallel-plate, electrostatic actuators and the tip-in instability," J. Microelectromech. Syst., vol. 12, pp. 656-671, 2003. 
[24] E. S. Hung and S. D. Senturia, "Extending the travel range of analog-tuned electrostatic actuators," J. Microelectromech. Syst., vol. 8, pp. 497-505, 1999.

[25] J. I. Seeger and S. B. Crary, "Stabilization of electrostatic actuated mechanical devices," in Proc. Tranducers 1997, Chicago, IL, pp. 1133-1136.

[26] E. K. Chan and R. W. Dutton, "Electrostatic micromechanical actuator with extended range of travel," J. Microelectromech. Syst., vol. 9, pp. 321$328,2000$.

[27] J. I. Seeger and S. B. Crary, "Dynamics and control of parallel plate actuators beyond the electrostatic instability," in Proc. Tranducers 1999, Sendai, Japan, pp. 474-477.

[28] L. Castañer, J. Pons, R. Nadal-Guardia, and A. Rodríguez, "Analysis of the extended operation range of electrostatic actuators by current-pulse drive," Sens. Actuators A, Phys., vol. A90, pp. 181-190, 2001.

[29] R. Nadal-Guardia, A. Dahé, R. Aigner, and L. M. Castañer, "Current drive methods to extend the range of travel of electrostatic microactuators beyond the voltage pull-in point," J. Microelectromech. Syst., vol. 11, pp. 255-263, 2002.

[30] J. I. Seeger and B. E. Boser, "Charge control of parallel-plate, electrostatic actuators and the tip-in instability," J. Microelectromech. Syst., vol. 12, pp. 656-671, 2003.

[31] P. B. Chu and K. S. Pister, "Analysis of closed-loop control of parallelplate electrostatic microgripers," in Proc. IEEE Conf. Robot. Autom., San Diego, CA, May 1994, pp. 820-825.

[32] L. A. Rocha, E. Cretu, and R. F. Wolfenbuttel, "Displacement model for dynamic pull-in analysis and application in large-stroke actuators," in Proc. Eurosensors XVII, 2003, pp. 448-451.

[33] Y. Sun, D. Piyabongkarn, A. Sezen, B. J. Nelson, and R. Rajamani, “A high-aspect-ratio two axis electrostatic microactuator with ectended travel range," Sens. Actuators A, Phys., vol. A102, pp. 49-60, 2002.

[34] J. Milne, J. Dell, A. Keating, and L. Faraone, "Extended tuning range Fabry-Perot etalon with doubly-supported beam actuators," in Proc. IEEE/LEOS Int. Conf. Opt. MEMS Their Appl., pp. 134-135, 2006.

[35] L. A. Rocha, E. Cretu, and R. F. Wolfenbuttel, "Using dynamic voltage drive in a parallel-plate electrostatic actuator for full-gap travel range and positioning," J. Microelectromech. Syst., vol. 15, pp. 69-83, 2006.

Jaroslaw Antoszewski received the Master's degree in physics from the Teachers College in Olsztyn, Olsztyn, Poland, in 1977, and the Ph.D. degree in semiconductor physics from the Institute of Physics of Polish Academy of Science, Warsaw, Poland, in 1982.

During 1982-1990, he was a Researcher and then a Project Leader in the R\&D Laboratory, WILMER Ltd., Warsaw, where he was engaged in design and testing of infrared radiometers for industrial applications. In 1991, he joined the Microelectronics Research Group, The University of Western Australia, Crawley, W.A., Australia, where he has been engaged in magneto-transport studies of semiconductor materials, and physics and technology of infrared detectors. His current research interests include development of technology merging IIVI and III-V based infrared detectors with microelectromechanical (MEMS) technology into a new technology for monolithic, tunable infrared sensors.

Kevin J. Winchester (S'00-M'01) received the B.Sc., B.E., and Ph.D. degrees in physics, electrical and electronic engineering, and electronic engineering, respectively, from The University of Western Australia, Crawley, W.A., Australia, in 1996 and 2004.

He was with Orbital Engine Corporation, Balcatta, Australia, and then, at Applied Optoelectronic, Inc., Texas. He joined the Microelectronics Research Group, The University of Western Australia, as a Senior Research Fellow, where he was engaged in research on plasma-based low-temperature microelectromechanical (MEMS) deposition technologies. In 2005, he joined MRX Technologies Pty. Ltd., West Perth, W.A., where he is a Project Engineer.
Thuyen Nguyen received the B.Sc., B.E., and Ph.D. degrees (with honors), in physics, electrical and electronic engineering, and electronic engineering, respectively from the University of Western Australia, Crawley, W.A., Australia, in 1998, 2000, and 2005, respectively.

He was engaged in research on the technology of HgCdTe-based infrared detectors. During 2003-2005, he was with the Microelectronics Research Group, The University of Western Australia, as a Senior Engineer, where he was engaged on integration of infrared detectors with microelectromechanical (MEMS) based infrared filter into one monolithic process. Since 2006, he has been with Origin Energy Solar, Regency Park, S.A., Australia, as a Senior Engineer.

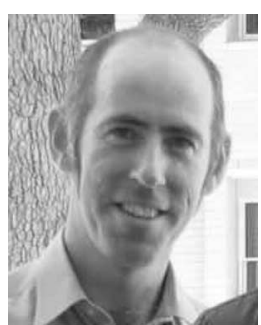

Adrian J. Keating (M'89-SM'06) received the B.E. degree in electrical/electronic engineering and the Ph.D. degree in photonics from the University of Melbourne, Melbourne, Australia, in 1989 and 1995, respectively.

In 1996, he joined Nippon Telegraph and Telephone (NTT), Japan, where he was engaged in developing optoelectronic switching testbeads, and also authored three Japanese patents. In 1998, he joined the University of California, Santa Barbara, where he was engaged in investigating optical switching, 1.55 $\mu \mathrm{m}$ vertical-cavity surface-emitting lasers (VCSELs), and optical amplifiers. In 1999, joined Calient Networks, where he was enagged in developing optical technologies for a microelectromechanical (MEMS) based optical system, and his work resulted in four patents. In 2004, he joined The University of Western Australia, Crawley, W.A., Australia. His current research interests include optical systems, microfluidics, porous silicon, and MEMS.

K. K. M. B. Dilusha Silva received the B.Sc. and B.E. degrees (with first class honors) in physics and electrical and electronic engineering, respectively, and the Ph.D. degree in biomedical engineering from The University of Western Australia, Crawley, W.A., Australia, in 1995, 1997, and 2004, respectively.

$\mathrm{He}$ has been engaged in the field of medical optics and instrumentation. From 2004 to 2006, he was engaged in the broader field of optics, completing two postdoctoral fellowships. The first postdoctoral fellowship focused on the development of an infrared optical microspectrometer, while the second resulted in the development of a modeling tool for atmospheric optical propagation. Since 2006, he has been a Senior Electronics Engineer at MRX Technologies Pty. Ltd., West Perth, W.A. His current research interests include optics and instrumentation.

Charles A. Musca (M'99) received the B.E. and Ph.D. degrees in electrical and electronic engineering from The University of Western Australia, Crawley, W.A., Australia, in 1997 and 1986, respectively.

For the past ten years, he has been an Electronics Design Engineer at The University of Western Australia, where he is currently an Associate Professor. His current research interests include semiconductor materials and device characterization with particular emphasis in infrared technology. 
John M. Dell (M'89) received the B.E. degree (with honors) and the Ph.D. degree in electronic engineering from The University of Western Australia, Crawley, W.A., Australia, in 1980 and 1989, respectively.

From 1984 to 1993, he worked in industry in Australia and France. His industrial experience includes molecular beam epitaxy (MBE) based optoelectronic integrated circuit (OEIC) technologies in III-V semiconductors, photonics devices and systems, and space radiation effects in electronics and optoelectronics. Since 1994, he has been a Member of the Academic Staff, The University of Western Australia. His current research interests include general areas of photonics, semiconductor materials, radiation effects, and recently microelectromechanical (MEMS).

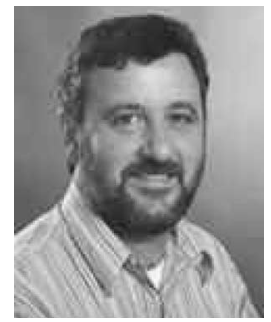

Lorenzo Faraone (M'79-SM'03) was born in Italy, on October 26, 1951. He received the B.E. and Ph.D. degrees in electrical and electronic engineering from the University of Western Australia (UWA), Crawley, W.A., Australia, in 1979.

During 1979-1980, he was a Research Scientist in the Sherman Fairchild Laboratory, Lehigh University, PA, where he was engaged in studies on MOS devices. From 1980 to 1986, he was a Member of the Technical Staff, RCA Laboratories, David Sarnoff Research Center, Princeton, NJ, where he has also been a Project Leader in the area of very large-scale integration (VLSI) CMOS technologies and a Principal Investigator of a research team studying space radiation effects in silicon-on-sapphire MOS-integrated circuits. In 1987, he joined the School of Electrical, Electronic and Computer Engineering, UWA, as a Senior Lecturer, and was promoted to an Associate Professor in 1993 and a Professor in 1998, and from 1999 to 2003, he was the Head of the Department/School. He currently holds more than ten U.S. patents. He is also the author or coauthor of more than 200 refereed published technical papers. His current research interests include the area of nonvolatile memory technology, compound semiconductor materials and devices, and microelectromechanical systems (MEMS), in particular, mercury cadmium telluride materials and device technologies for infrared detector arrays, gallium nitride technology for ultraviolet detectors and high-speed/high-power electronics, and MEMS technologies for tunable optical cavity detectors.

Prof. Faraone was the recipient of the RCA Laboratories Individual Outstanding Achievement Award in 1983 and 1986, and the John de Laeter Innovation Award in 1997. He is a member of the Fellow of the Australian Academy of Technological Sciences and Engineering (FTSE) and the Fellow of the Australian Academy of Science (FAA). 